\title{
Medical Psychology Services in Dutch General Hospitals: State of the Art Developments and Recommendations for the Future
}

\author{
Paul Soons · Johan Denollet
}

Published online: 6 March 2009

(c) The Author(s) 2009. This article is published with open access at Springerlink.com

\begin{abstract}
In this article an overview is presented of the emergence of medical psychology in the care of somatically ill patients. The situation in the Netherlands can be considered as prototypical. For 60 years, clinical psychologists have been working in general, teaching and academic hospitals. Nowadays, they are an integrated nonmedical specialism working in the medical setting of hospitals in the Netherlands, and are a full-member of the medical board. This paper discusses several topics: the position of the general hospital in the health care system in the Netherlands, the emergence of medical psychology in Dutch hospitals, the role of the professional association of medical psychologists, and the characteristics of patients seen by clinical psychologists. Following the discussion about the situation of medical psychology in other countries, recommendations are formulated for the further development of medical psychology in the Netherlands as well as in other countries.
\end{abstract}

Keywords Medical psychology ·

General, teaching and academic hospitals - Clinical care . Education

Medical psychology is an emerging discipline in general hospitals all over the world. There is wide variation in penetration of this profession in the hospitals, their place in the organization, the patients seen and the financing of their work. In this article, we describe the development of

P. Soons $(\square) \cdot$ J. Denollet

Department of Medical Psychology, CoRPS - Center of

Research on Psychology in Somatic Diseases, Tilburg

University, P.O. Box 90153, 5000 LE Tilburg, The Netherlands

e-mail: p.soons@uvt.nl medical psychology over the last 60 years in the Netherlands. We investigate the state of the art, the recent and oncoming developments and challenges medical psychologists will face, and we formulate recommendations on how to enhance the development of this profession. We consider the situation in the Netherlands as an example of how medical psychology can be developed and implemented in clinical care. We hope to contribute to an internationally focused discussion about a more unified vision on the practice of medical psychology. In our vision there should be internationally accepted standards about organizing and financing psychological care in hospitals.

\section{General Hospital in the Netherlands}

The Netherlands has about $16,000,000$ inhabitants. There are about 100 general hospitals (16 of these are teaching hospitals) and eight academic hospitals in the Netherlands. A general hospital is an institution of the second line in the Dutch health care system. All patients who come to the hospital, whether inpatient or outpatient, are referred by the general practitioner (first line). The general practitioner is the main port to the hospital, but in the first line there are more professionals (social worker, physiotherapist, nurse and also psychologists). Here patients are treated with relatively simple/mild medical, social and psychological problems. When hospital care is needed the general practitioner refers the patients to a medical specialist (Soons, 2002). In the Netherlands, patients can only consult a medical specialist after being referred by the general practitioner; however, the general practitioner can not refer patients to a medical psychologist in the hospital directly.

The primary task of a general hospital is to see patients for medical diagnosis and treatment at a medical specialist 
level. The general practitioner can be considered as working at a generalist level. Patients can be treated on the ward, at a daytime treatment department, or in an outpatient clinic. In the Netherlands in total about 55,000 hospital beds are available. There are about 1.5 million newly referred clinical patients a year, about 1 million new daytime patients and about 8.5 million new outpatient patients are seen (Soons, 2006).

In the general hospitals, clinical care is provided by the medical specialist including the internist, neurologist, psychiatrist, cardiologist, pediatrician, gynecologist, geriatrician, ENT-specialist, orthopedic surgeon, general surgeon, dermatologist, oculist, urologist, lung specialist and rehabilitation physician. These medical specialists get their own patients from the general practitioner and have a ward and beds for their specialty. About $40 \%$ of all hospitals have a psychiatric ward.

There are several medical specialists who do not have their own patients, but who support the medical specialities mentioned above: the anesthesiologist, radiologist, microbiologist and pathologist.

In addition there is a number of non-medical professionals who have completed a post-graduated (specialization) training of about 4 years. These are: the clinical chemist, clinical physicist, hospital pharmacologist and clinical psychologist. As such, the clinical psychologist is a full-member of the medical staff, which is the main advisory board of the administration of the hospital. They have the same or comparable privileges as medical specialists, for example with regard to salary, the right to advise the administration of the hospital and the right to refer patients.

Finally the following disciplines (non-members of the medical staff) can be found in hospitals: the pastoral worker, physiotherapist, social worker, dietician and of course the nurses (Soons, 2002).

\section{Costs of Health Care}

The national income of the Netherlands in 2004 was about 490 billion EUROs. The costs of healthcare in 2004 amounted to about 60 billion EUROs, about $12.3 \%$ of the national income. The total costs of the hospitals amounted to 18 billion EUROs.

Estimation of the cost of medical psychology is about 60 million EUROs a year. That means that the cost of care of one patient in the department of medical psychology is about 1500 EUROs on average. This includes the psychodiagnostic and treatment sessions by the psychologist plus sessions by other department of medical psychology workers. The number of sessions can vary widely and of course not all patients are tested.

\section{The Emergence of Medical Psychology in Dutch Hospitals: History and Figures}

Since about 1950, the first psychologists have been working in general and academic Dutch hospitals. In 1972 health insurance organizations positively agreed about the usefulness of psychologists working in hospitals. In the seventies and eighties, there was at least one psychologist working in 120 hospitals. Nowadays there are about 400 psychologists (part-timers included) working in about 100 hospitals. Almost all psychologists are member of the medical staff and are part of an autonomous department of medical psychology (Vos \& van Lieshout, 1990; Neijmeijer \& Hutschemakers, 1995; Soons, 2002).

The following disciplines are working in the autonomous departments of medical psychology: psychologists (who have finished their master's degree), health psychologists (who have finished an additional two-year education), clinical psychologists (who have finished an additional four-year education, after completing the health psychology level), psychological assistants, psychological workers, secretaries, master students and trainees, and trainees becoming health psychologist or clinical psychologist. Psychological assistants and psychological workers perform a part of the diagnostic process, especially testing. They also perform elements of treatment, for example relaxation training or biofeedback training. One of the psychologists is head or coordinator of the department. On average there are about four FTEs (full-time equivalents), including all disciplines. Patients can not self refer as all psychological services are only provided after a medical specialist makes a referral to the medical psychologist who is considered to be additional to medical treatment.

In the Netherlands there are eight medical schools where psychologists are also employed. However, no data are available about how many psychologists are employed there and whether they are treating patients, in addition to conducting research and teaching courses for medical students.

\section{Characteristics of the Population}

Each year about 40,000 patients in the Netherlands are referred to a psychologist. A full-time psychologist sees 175 newly referred patients a year on average (Klip, Fekkes, \& Timmermans, 1996; Soons, 2005b). To consider this information in context, it is important to realize that research estimates suggest that $30 \%$ of somatic patients need some form of help in the psychosocial realm (Poppelaers \& Kapteijn, 1994). When we calculate all new patients who come to the hospital on an annual basis in the 
Netherlands this amounts to a total of 11 million. Of these 1.5 million are clinical patients, 1 million are daytime patients and 8.5 million are out-patients. Thus, we can conclude that about $0.37 \%$ of all newly referred patients are seen by psychologists working in general hospitals (Soons, 2006). For more details about the types of patients and sources of referral please see Table 1 .

Sixty percent of patients seen by psychologists are female and 66\% are between 15 and 64 years old. Onethird of all patients is referred to the clinic, and $67 \%$ on an outpatient basis. The duration of treatment is less than half a year. The main referring specialists are: neurologist, psychiatrist, pediatrician and internist. The average number of sessions a patient receives is less than 10 (Soons, 2000).

Five categories of patients (as listed below) are frequently referred to the psychologist; each category representing about one-fifth of referrals (Sweet, Rozensky, \& Tovian, 1991; Hemmer, Jeuken, Veenstra, Wernsen, \& Swaak-Beuken, 1997; Soons, 2002, 2006):

(1) Adult patients with chronic diseases. Psychologists see many patients with chronic conditions who are at risk for psychological problems, like patients with lung diseases (Deenen \& Klip, 1993), heart diseases (Denollet \& Brutsaers, 2001), cancer (Meyer \& Mark, 1995) and diabetes mellitus (Henry, Wilson \& Bruce, 1997). The psychological concerns may be the sequelae of the medical condition, but it is also possible that there is no connection with the disease process. In some cases there may be a biological basis for the mental health condition, e.g. depression. In other cases the stress of having a disease and limitations created by the disease may lead to

Table 1 Patients

\begin{tabular}{ll}
\hline Patients* & Main referring specialists \\
\hline Neuropsychology & Neurologist \\
& Internist \\
& Geriatrician \\
Psychiatric & Psychiatrist \\
Children & Pediatrician \\
& Dermatologist \\
& Surgeon \\
Somatic diseases & Internist \\
& Neurologist \\
Medically unexplained symptoms & Cardiologist \\
& Gynecologist \\
& Urologist \\
& Lung specialist \\
\hline
\end{tabular}

* Each category represents approximately $20 \%$ of the types of referrals made to medical psychology psychological problems. The task of the psychologist can be to clarify the situation for the patient and to enhance their insight into their circumstances. The psychologist can also help the patient cope with his/ her disease.

(2) Patients with functional complaints who present somatic complaints, in the absence of a clear medical cause (e.g. functional headache or pain in the stomach). These patients tend to shop in the medical world or go to alternative doctors. The psychologist can play an important role for these patients to help them gain insight into their condition and help them stop medical shopping as well as teach them new coping styles. The following medical specialists refer most of the adult patients with somatic complaints: internists, cardiologists, gynecologists, urologists, and dermatologists.

(3) Adult patients with (suspected) brain damage, who need neuropsychological assessment and treatment (e.g. stroke, dementia, epilepsy, brain tumors). The targets for the clinical psychologist are threefold: to help the medical specialist with differential diagnosis, to investigate cognitive functioning (e.g. concentration and memory) and to provide treatment to enhance functioning. The main referring medical specialists are neurologists, geriatricians and internists.

(4) Children up to 18 years of age, with a variety of diseases and symptoms. These patients can be divided into four primary groups: (a) children with psychosomatic disorders, headache, sleep problems, eating disorders, encopresis, enuresis and constipation; (b) children with chronic medical diseases, like COPD, diabetes; (c) children with suspected developmental disorders; and (d) children with acquired brain damage. The referring medical specialist is almost always a pediatrician.

(5) Adult psychiatric patients with primary psychiatric conditions, e.g. anxiety disorders, phobias, panic disorders, depression, personality disorders, PTSD. Patients are exclusively referred by the psychiatrist. About 40 general hospitals have a psychiatric ward, most of these have a daytime treatment department. About 50 hospitals have a psychiatric poly-clinic.

Across hospitals there appears to be a great diversity in referral patterns and therefore also in the population of the departments of medical psychology (Jabaay, Goudriaan \& Hutschemaekers, 2000; Soons, 2000). This diversity is determined by the specific circumstances of a medical psychology department (hospital, the affinity of psychologists and medical specialists), as there is no clear consensus on what constitutes good practice and the financing of patient care, which can vary widely among departments. 


\section{The Task of Psychologists in the Medical Setting}

The first task of the medical psychologist is assessment of the patient and his complaints by interviewing, observation and testing (Hemmer et al., 1997; Fiedeldij Dop \& Verhaak, 2000; Soons, 2002, 2006). Sometimes, the referral reason is not clear as the referral question is not articulated well (Belar \& Deardorff, 1995).

The second task is psychological (often behavioral) treatment, which generally is a short-term intervention (less than half a year). These two tasks relate to direct interaction with the patient. There are also indirect, patient related tasks: i.e. teamwork, teamcoaching, consultation of other professionals.

Finally, there are tasks which are not related to the clinical care of patients: participating in staff committees (for example the ethical committee), management tasks and training of master students and post-graduate students (internship). Research is not a structural task in general in teaching hospitals; of course, this is evidently the case in academic hospitals.

Often some kind of sub-specialization appears regarding the five categories of patients: one psychologist for both categories of adult (psycho)somatic patients, one for patients with (suspected) brain damage (a clinical neuropsychologist), one for psychiatric patients and one psychologist for children. All psychologists are based in the department of medical psychology. When a medical speciality refers many patients for psychological care, a psychologist may be directly allocated to that department or specialism (e.g. psychiatry, pediatrics, etc.).

\section{Education and Professional Development of Psychologists in the Medical Setting}

The education of a medical psychologist starts with a bachelor's degree in psychology, which takes 3 years. Then the student chooses a master in psychology which is oriented towards practical psychology, like health psychology or medical psychology (1 or 2 year programs).

However, when students have finished a master degree, they are not allowed to work autonomously in clinical patient care. In order to do so, they first need to register for post-graduate education during a 2 year internship that eventually may lead to certification as a health psychologist. This is a general professional qualification which allows the health psychologist to provide services autonomously with patients, similar to a dentist. The next educational step, if pursued is a 4 year internship as a behavioral specialist, which leads to a state certification of clinical psychologist, a specialist profession, like the medical specialist (Soons \& Albrecht, 2005). Since 2005 the registration as a psychotherapist is included in the registration as a clinical psychologist. In total it takes 10-11 years to become a behavioral specialist.

All psychologists in hospital departments of medical psychology have completed university degrees and most have completed further education. Ninety percent have completed the registration as a clinical psychologist: emphasis is on psychodiagnostics and simple psychological treatment; $50 \%$ are registered as a psychotherapist, which is a multi-theoretical education. About $50 \%$ have completed the education as a behavioral and cognitive therapist; and about $90 \%$ has some basic education in cognitive and behavioral therapy (Soons, 2004c).The cognitive-behavioral approach is widespread and it is the main theoretical and practical framework in treating adults and children with psychiatric, somatic and neuropsychological complaints. About $15 \%$ of psychologists have a Ph.D. (Hout van, 2005).

\section{The Dutch Professional Associations}

The PAZ (Dutch Association of Psychologists working in Hospitals) is a division of the Netherlands Institute of Psychologists (the Dutch counterpart of the APA). The LVMP (Dutch Association of Medical Psychologists) is an autonomous association, which performs special activities, like funding and organizing symposia. These two organizations work closely together to promote the interests of psychologists working in a medical setting. They have a common administration and a common website (www. lvmp.nl). The aim of the PAZ/LVMP is to contribute to the scientific level of medical psychology in hospitals and to assist its members with problems at the organizational level. It promotes contact between members, and considers a very high standard of quality of performance to be essential for the strengthening of the relatively new position of its members as behavioral specialists in the medical field. Three times a year there is a general meeting that includes an invited lecture about new developments, research findings and special organizational aspects of medical psychology.

Since 1993, a visitation committee has been inspecting the departments of medical psychology around the country (Wiersma \& Tromp, 1999). The quality committee develops standards for all kinds of aspects of professional functioning of its members, and coordinates the development of informational material for patients and referring medical specialists on a wide range of topics (Soons, 2004b). Yearly, the scientific committee organizes a scientific conference on topics in the field of medical or hospital psychology (Soons, 2005a, c) and all members of the LVMP are also members of the International Society of 
Behavioral Medicine (ISBM) (website: www.ISBM.com) and its Dutch branch the Dutch Behavior Medicine Federation (NBMF) (website: www.nbmf.nl). In order to strengthen the position of psychologists in the medical setting a special taskforce is developing a diagnosis-treatment based financial system, in which the costs for medical psychological services are calculated in conjunction with other medical activities. The PAZ has been and still is very active in striving for the improvement of the legal position of the clinical psychologist to the same level as the medical specialist in the governmental registration system for health professionals.

\section{Medical Psychology in the International Context}

Empirical data about how medical psychology has developed across different countries worldwide is limited outside the Netherlands. Nevertheless, there have been some attempts to survey medical psychology in Australia (Groth-Marnat, 1988), Germany (Herzog \& Hartmann, 1990), South-Africa (Schlebusch \& Simpson, 1987) and the United States of America [USA] (Tovian, Rozensky, \& Sweet, 2003; Pate \& Kohout, 2005).

In 2001, an overview was published on how medical psychology has emerged in several countries in the 20th century (Wedding, 2001). The following countries were included: Australia, Brazil, Canada, Catalonia, Greece, India, Iran, Israel, New Zealand, Russia and Thailand. No empirical data were reported about numbers of hospitals, psychologists and patients, etc., but the conclusion was drawn that overall there are countries where the system of medical psychology is very similar to the USA (e.g. Canada, New Zealand and Australia) while there is another group that is very dissimilar to the USA (e.g., India, Iran, Thailand and Catalonia).

Unfortunately not much empirical data are available about the state of the art of medical psychology in the hospitals around the world. In general, there is much variation in clinical practice between departments and between countries (Soons 2004a, d). Many different levels of development have been found in hospitals in countries and between countries, as well as a great diversity regarding the organization of medical psychology in hospitals. There are also substantial differences in the number of psychologists employed in hospitals and as to how many and what patients are referred by medical specialists to psychologists. Apparently, medical psychology services are emerging and developing in different degrees and this professional non-medical speciality is not well established in all hospitals through all countries yet. Thus, in summary, there is a need for more and accurate empirical data to make the day to day practice of medical psychology more transparent. Above all, a real consensus about how to organize medical psychology services in hospitals and what patients should be referred is necessary.

\section{Future Developments and Recommendations}

What is needed for a further development and professionalization of medical psychology in hospitals? We would suggest that, in order to fully integrate in the hospitals, it is necessary for medical psychology to take a number of strategic steps.

\section{Practice-Oriented Research}

For the further professionalization of medical psychology, it is necessary that there is more practice-oriented and evidence-based research to improve and promote day to day practice in the field of medical psychology in hospitals. For example, we need more empirical data about daily practice patterns (e.g. what patients with what characteristics are seen, how many psychologist are working in the hospitals). This is necessary for adequate policy making. Routine-based and standard registration and monitoring of simple data are crucial to gain more transparency for ourselves and policymakers in what we do. Currently, data regarding the number and diagnostic issues of patients and treatment procedures used are not available. Further, data from simple measures added as a matter of practice, e.g. simple effect measures, patient satisfaction measures, quality of life measures, and test data for the development of norm groups, could assist to formulate and evaluate policies.

It is important that patients who need medical psychology interventions be referred and selection of high-risk patients is of great importance. The design and implementation of screening instruments or procedures on the basis of which patients can be referred to psychologist, should be promoted. In practice there is a great variety in the referral patterns between departments in hospitals, between hospitals and between countries. The expectation is that more patients should be referred to the psychologist, but also that the indication should be refined. Only those patients who explicitly need psychological help, should actually get it and studies assessing psychological issues that present in medical populations can drive this refinement. For example, Hemert, Hengeveld, Bolk, Rooijmans, and Vandenbroucke (1993) assessed the prevalence and type of psychiatric disorders in relation to medical diagnostic findings within a general internal medicine outpatient clinic. The prevalence of psychiatric disorders was $15 \%$ for patients with a medical explanation for their presenting symptom, $45 \%$ for patients with ill-explained and 
$38 \%$ for those with unexplained symptoms. Additionally, Nimnuan, Hotopf, and Wessely (2001) investigated the prevalence among new patients of medically unexplained symptoms across diverse specialties: gastroenterology, gynecology, neurology, rheumatology, chest, cardiology and dentistry. They found that $52 \%$ fulfilled criteria for medically unexplained symptoms. The highest prevalence was among patients of the gynecology outpatient clinic (66\%). Data from studies such as these could help psychology target higher risk populations.

Finally, it is necessary to know which interventions with what patients are efficient and cost-effective. A lot of studies have been performed in this area, but they are perhaps not convincing enough for decision- and policymakers. One very important study is the report of the Canadian Psychological Association (Hunsley, 2002). Medical cost offsets due to medical psychological intervention has been found for numerous conditions and diseases, including heart disease, hypertension, diabetes, cancer and chronic pain. As to both effectiveness and cost-effectiveness studies we can conclude as Hunsley (2002) did: "There is clear and compelling evidence that psychological interventions can effectively treat a wide range of child and adult health problems. Psychological treatment can also be a very costeffective form of treatment and may even be more costeffective than commonly used pharmacological interventions. Psychological interventions also have the potential to reduce health care costs, as successfully treated patients typically reduce their utilization of other health care services. In some instances, the reduced cost to the health care system may actually be higher than the cost of the psychological service, thus resulting in a total cost offset to the system". Just as importantly medical psychology treatment may significantly enhance medical prognosis (Veenstra \& Fonk, 2006).

\section{Patient Care}

Adequate financing of psychological work in the medical setting is needed. There should be more opportunities for prevention of recidivism and the psychological treatment of patients with chronic diseases, like coronary heart diseases and diabetes mellitus. Not only should there be space for treating patients for current problems, but also secondary prevention and lifestyle change should receive attention. Disease management (Chronic Disease Management website: www.Calgaryhealthregion.ca) might be the right financial procedure to manage this. The current financing is a major cause of the great diversity of practices in medical psychology departments.

The formulation of protocols and standards, preferably on a multidisciplinary basis, is necessary as a basis of evidence and also as a basis for financing. There should be more consensus about what constitutes good clinical practice. This is the other major cause of the great diversity of practices in medical psychology departments.

Psychologists in a medical setting should not only treat patients directly, but should also enhance their consultation function to advice other disciplines in the hospitals.

An adequate division of work for medical patients in primary care (first line) and secondary care (hospital) should be established for both patients with chronic diseases, and for patients with functional complaints. In the first line there should be standard care for patients who need medical psychology interventions and in the second line there should be the possibility for specialized medical psychology care. The psychologists in the hospitals and those working in the first line should cooperate to provide a broad package of medical psychology interventions that will fufill the need of all patients from a specified region.

The Education of Psychologists as Scientist-Practitioners

In terms of basic education, training of psychologists who will be working in a medical setting should be more focused on medical aspects of patient care. Nowadays, the basic education of psychologists who are working in the medical context is too much based on a mental health view of patients and the help they need. Starting with the master program, their education should be more focused on medical aspects. Such a program at Tilburg University, a two-year master program in Medical Psychology, was started in September 2006 to address this need for psychologists to have a basic training in the medical context. This master program involves courses in medical psychology and medical conditions, research training, a one-year clinical internship, and a master thesis dealing with research in medical populations.

In terms of post-graduate education, the training of health psychologists (a generalist education) and clinical psychologists (a specialist education) should require a more specialized track focusing on medical psychology. Needless to say, an adequate financing system for graduate and post-graduate education should be established.

\section{Conclusions}

Medical psychology performed by clinical psychologists is a fairly well established non-medical speciality in the medical setting of general and academic hospitals in the Netherlands. Medical psychological care is available nationwide and not restricted to some hospitals or specific areas. However, not much empirical data are available about the presence and characteristics of medical psychology departments in other countries. 
Despite gains in the Netherlands much is left to be done to fully integrate medical psychology in hospitals. There remains considerable variation in clinical practice between medical psychology departments and between psychologists, as well as between countries. This is due to the fact that there is not enough consensus on how to screen and treat patients. As a result, many patients and patient populations are under-treated or over-treated. In addition, there is a wide variation in the possibilities of financing medical psychological care. Practice oriented research seems to be a powerful instrument to fill this gap. To accomplish this, it will be necessary to register and monitor every day practice, select patients who need medical psychological care more adequately and initiate projects to assess the costeffectiveness of medical psychological intervention in every day practice.

Acknowledgement This study was supported by VICI Grant \# 45304-004 from the Netherlands Organization For Scientific Research (The Hague, The Netherlands) to Dr. Johan Denollet.

Open Access This article is distributed under the terms of the Creative Commons Attribution Noncommercial License which permits any noncommercial use, distribution, and reproduction in any medium, provided the original author(s) and source are credited.

\section{References}

Belar, C. D., \& Deardorff, W. W. (1995). Clinical health psychology in medical settings. A practitioner's guidebook. Washington DC: APA.

Deenen, T. H., \& Klip, E. C. (1993). Coping with astma. Respiratory Medicine, 87, 67-80.

Denollet, J., \& Brutsaers, D. L. (2001). Reducing emotional distress improves prognosis in coronary heart disease: 9-year mortality in a clinical trial of rehabilitation. Circulation, 104, 2018-2023.

Fiedeldij Dop, M. J. C., \& Verhaak, P. F. M. (2000). Psychologen in de Algemene Gezondheidszorg. In A. A. Kaptein, B. Garssen, J. Dekker, H. W. J. van Marwijk, P. J. G. Schreurs, \& R. Beunderman (Eds.), Psychologie en geneeskunde (pp. 32-47). Houten: Bohn Stafleu Van Loghum.

Groth-Marnat, G. (1988). A survey of the current and future directions of professional psychology in acute general hospitals in Australia. Australian Psychologist, 23, 127-135.

Hemert, A. M., Hengeveld, M. W., Bolk, J. H., Rooijmans, H. G. M., \& Vandenbroucke, J. P. (1993). Psychiatric disorders in relation to medical illness among patients of a general medical outpatient clinic. Psychological Medicine, 23, 167-173.

Hemmer, G. F. J., Jeuken, J. M. G., Veenstra, A. C., Wernsen, R. L., \& Swaak-Beuken, Y. J. M. (1997). De klinisch psycholoog in het algemeen, academisch en categoraal ziekenhuis. Amsterdam: NIP.

Henry, J. L., Wilson, P. H., \& Bruce, D. G. (1997). Cognitivebehavioural stress management for patients with non-insulin dependent diabetes mellitus. Psychological Health and Medicine, 2, 109-118.

Herzog, T., \& Hartmann, A. (1990). Psychiatrische, psychosomatische und medizinpsychologische Konsiliar- und Liaisontatigheit in der Bundesrepublik Deutschland: Ergebnisse einer Umfrage. Nervenartz, 61, 281-293.
Hout van, G. (2005). Promotie: Promoveren en motivatie. In P. H. G. M. Soons \& R. Albrecht (Eds.), De klinisch psycholoog in het algemene ziekenhuis. Een scientist-practitioner in een netwerk (pp. 23-28). Amsterdam: NIP/PAZ.

Hunsley, J. (2002). The cost-effectiveness of psychological interventions. Report by the Canadian Psychological Association (ISBN:1896538703).

Jabaay, L., Goudriaan, I., \& Hutschemaekers, G. (2000). De klinisch psycholoog in het algemeen ziekenhuis. Een praktijkstudie naar de functie-uitvoering van klinisch psychologen en de waardering daarvan door patienten. Utrecht: Trimbos-instituut.

Klip, E. C., Fekkes, J., \& Timmermans, L. J. M. (1996). Klinisch psychologen in het algemeen ziekenhuis. In W. T. A. M. Everaerd (Ed.), Handboek klinische psychologie (pp. 1-19). Houten: Bohn Stafleu Van Loghum.

Meyer, T. J., \& Mark, M. M. (1995). Effects of psychosocial interventions with adult cancer patients: A meta-analysis of randomized experiments. Health Psychology, 14, 101-108.

Neijmeijer, L., \& Hutschemaekers, G. (1995). GGZ in het algemene ziekenhuis. Utrecht: Nederlands Centrum voor Geestelijke Volksgezondheid.

Nimnuan, C., Hotopf, M., \& Wessely, S. (2001). Medically unexplained symptoms: An epidemiological study in seven specialities. Journal of Psychosomatic Research, 51, 361-367.

Pate, W. E., \& Kohout, J. L. (2003). Results from a national survey of psychologists in medical school settings-2003. Journal of Clinical Psychology in Medical Settings, 12, 203-208.

Poppelaers, C. A. M., \& Kapteijn, A. A. (1994). Psychologische en psychiatrische problematiek bij chronisch somatisch zieken. Overzichtsstudie. Zoetermeer: Nationale Commissie Chronisch Zieken.

Schlebusch, L., \& Simpson, M. A. (1987). Medical psychology-its growth and development in South African medical schools. South African Medical Journal, 72, 413-416.

Soons, P. H. G. M. (2000). Fifty years of medical psychology services in Dutch general hospitals. International Journal of Behavioral Medicine, 7(Suppl), 223-224.

Soons, P. H. G. M. (2002). De psycholoog in het algemeen ziekenhuis. In A. J. J. M. Vingerhoets, P. F. M. Kop, \& P. H. G. M. Soons (Eds.), Psychologie in de gezondheidszorg. Een praktijkorientatie (pp. 71-96). Houten: Bohn Stafleu Van Loghum.

Soons, P. H. G. M. (2004a). Medical psychology in general hospitals internationally (abstract of ICBM-2004 Mainz). International Journal of Behavioral Medicine, 11(Suppl), 173.

Soons, P. H. G. M. (2004b). Kwaliteitsbeleid van de PAZ. Symposium Ziekenhuis en Geheugenpoli. Amersfoort (paper, 5 maart).

Soons, P. H. G. M. (2004c). Cognitive behavioral therapy in medical psychology departments in dutch general hospitals (abstract). World Congress of Behavioral and Cognitive Therapies 2004 (p. 183), Kobe, Japan.

Soons, P. H. G. M. (2004d). Medical psychology in general hospitals internationally. International Journal of Behavioral Medicine, 11(Suppl), 267.

Soons, P. H. G. M. (2005a). The scientist-practitioner in een network: Wat doet de PAZ ermee? In P. H. G. M. Soons \& R. Albrecht (Eds.), De klinisch psycholoog in het algemene ziekenhuis. Een scientist-practitioner in een netwerk (pp. 41-45). Amsterdam: NIP.

Soons, P. H. G. M. (2005b). Medische psychologie in het algemene ziekenhuis: Stand van zaken, ontwikkelingen en actiepunten voor de toekomst. In. Aanvraag master medische psychologie (pp. 115-118). Tilburg: Universiteit van Tilburg.

Soons, P. H. G. M. (2005c). Onderzoek in de praktijk: optiek van de $P A Z$. Paper invitational conference NBMF. Zeist, 16 November.

Soons, P. H. G. M. (2006). Psychologen in de somatische gezondheidszorg. In A. A. Kapteijn, R. Buenderman, J. Dekker, \& 
A. Vingerhoets (Eds.), Handboek medische psychologie (pp. 45-74). Bohm, Stafleu van Loghum: Houten.

Soons, P. H. G. M., \& Albrecht, R. (Eds.). (2005). De klinisch psycholoog in het algemene ziekenhuis als scientist-practitioner. Amsterdam: NIP.

Sweet, J. J., Rozensky, R. H., \& Tovian, S. M. (Eds.). (1991). Handbook of clinical psychology in medical settings. New York: Plenum.

Tovian, S. M., Rozensky, R. H., \& Sweet, J. J. (2003). A decade of clinical psychology in medical settings: The short longer view. Journal of Clinical Psychology in Medical Settings, 10, 1-8.
Veenstra, S., \& Fonk, M. (2006). Brug tussen lichaam en geest. Psychologische behandeling verbetert de medische prognose. Medisch Contact, 61, 1978-1980.

Vos, P., \& van Lieshout, P. (1990). De psycholoog in het algemeen ziekenhuis. Een overzicht. Nederlands Tijdschrift voor de Psychologie, 45, 49-57.

Wedding, D. (2001). Introduction to the special issue: Medical psychology around the world. Journal of Clinical Psychology in Medical Settings, 8, 1-2.

Wiersma, F. M., \& Tromp, C. N. (1999). 25 jaar Psychologie in Algemene/Academische Ziekenhuizen. Amsterdam: NIP. 